\title{
GESTÃO DO MARKETING EM MICRO E PEQUENAS EMPRESAS
}

Artigo recebido em: 07/10/2014. Artigo aprovado em: 26/06/2015.

\begin{abstract}
Ricardo Limongi França Coelho - Universidade Federal de Goiás ${ }^{1}$ Jaquelyne Resende de Miranda - Universidade Federal de Goiás ${ }^{2}$ Altair Camargo Filho - Universidade Federal de Goiás ${ }^{3}$ Maria Salete Batista Freitag - Universidade Federal de Goiás ${ }^{4}$ Marcos Inácio Severo de Almeida - Universidade Federal de Goiás ${ }^{5}$
\end{abstract}

Resumo: A literatura acerca de marketing empreendedor apresenta como o marketing pode contribuir na gestão das micro e pequenas empresas (MPEs) (CARSON, 1990; STOKES, 2000). Dessa forma, este estudo identificou as estratégias da gestão de marketing em MPEs a partir da aprendizagem dos gerentes-proprietários de 40 empresas localizadas em Goiânia e região metropolitana. A análise de dados ocorreu por meio da análise de discurso e a análise de conglomerados. Foi identificado que a aprendizagem dos gerentesproprietários ocorre por meio da observação da dinâmica do mercado e por meio de experiências realizadas no cotidiano. Concluiu-se, ainda, que os aspectos como o relacionamento, comunicação boca a boca e o diálogo com o cliente são praticados nas MPEs sem a consciência de serem ações de marketing sistematizadas.

Palavras-chave: Marketing; Marketing Empreendedor; Aprendizagem Gerencial; Método Misto; MPE.

\section{MARKETING MANAGEMENT IN MICRO AND SMALL ENTERPRISES}

Abstract: It's true that the literature on entrepreneurial marketing has contributed to the discussion of how marketing can contribute to the management of micro and small enterprises (SME) (CARSON, 1990; STOKES, 2000). So, this study identified the strategies of marketing management in SME (s) from learning of ownermanagers of 40 companies located in Goiania and the metropolitan region. Data analysis occurred through discourse analysis and cluster analysis. It was identified that the learning of owner-managers occured through observation of market dynamics and experiences in everyday life. Also concluded that aspects such as

\footnotetext{
${ }^{1}$ Endereço: Alameda Palmeiras, Quadra D, Campus Samambaia, Goiânia - GO, CEP 74001970,

Caixa Postal 131. E-mail: ricardolimongi@gmail.com

2 E-mail: jaquelyne.resende@gmail.com

${ }^{3}$ E-mail: altaircamargo@gmail.com

${ }^{4}$ E-mail: saleteufg@gmail.com

${ }^{5}$ E-mail: misevero@yahoo.com.br
}

COELHO, R. L. F.; MIRANDA, J. R.; CARMARGO FILHO, A.; FREITAG, M. S. B.; ALMEIDA, M. I. S. de. Gestão do marketing em micro e pequenas empresas. Revista de Empreendedorismo e Gestão de Pequenas Empresas, v.4, n.2, 2015. 
relationships, communication word of mouth and the dialogue with the customer are practiced in SME (s) without the awareness of being systematized marketing actions.

Keywords: Marketing; Entrepreneurial Marketing; Learning Management; Mixed Method; SME.

\section{Introdução}

Em geral, a gestão do marketing nas micro e pequenas empresas (MPE) é informal, casual e simples. Isso decorre diretamente do pequeno tamanho das empresas, sua informalidade e da forte influência do empreendedor em suas decisões (JONES; ROWLEY, 2011).

Pequenas empresas não são grandes empresas em miniaturas, já que possuem características e necessidades próprias (CARSON, 1990). Assim, as técnicas do marketing tradicional geralmente não se adaptam às suas realidades, pois demandam recursos que as MPEs não possuem (CARSON, 1990; SOLÉ, 2013). Por isso, o marketing implementado pelas MPEs é diferente do utilizado pelas grandes empresas, ou seja, do marketing tradicional, pois se trata de um exercício gerencial aprendido durante as experiências do cotidiano, quer sejam essenciais ou corriqueiras (SOLÉ, 2013). Essas experiências de aprendizagem podem ocorrer por tentativa e erro ou por observações (LEITE; GODOY; ANTONELLO, 2006), isto porque a formação gerencial formal não atende as demandas impostas pela dinâmica organizacional (MINTZBERG; GOSLING, 2003).

No contexto das MPEs, é o gerente-proprietário quem reconhece e explora as oportunidades do mercado, além de tomar as decisões tanto operacionais quanto estratégicas (MORRISH, 2011; ELMUTI; KHOURY; OMRAN, 2012). Ele escolhe com frequência a ação em detrimento da reflexão, o que pode acarretar prejuízos na qualidade das decisões. Ao não explorar a reflexão, deixa de descobrir novas alternativas para as suas práticas, além de perder a oportunidade de atuar no sentido de preparar e desenvolver sua equipe ao compartilhar informações relacionadas à dinâmica do negócio (MINTZBERG; GOSLING, 2003). Por tais razões, foi necessário desenvolver estudos de marketing para essas organizações: o marketing empreendedor (JONES; ROWLEY, 2011).

COELHO, R. L. F.; MIRANDA, J. R.; CARMARGO FILHO, A.; FREITAG, M. S. B.; ALMEIDA, M. I. S. de. Gestão do marketing em micro e pequenas empresas. Revista de Empreendedorismo e Gestão de Pequenas Empresas, v.4, n.2, 2015. 
O marketing empreendedor está relacionado com uma melhor determinação e busca por oportunidades de negócios pelas empresas, fazendo com que sejam mais ágeis em monetizar novas oportunidades diante de seus concorrentes (SOLÉ, 2013). Como o marketing empreendedor é realizado por empreendedores, suas características são semelhantes a aspectos empreendedores, tais como a orientação de perseguir oportunidades e lançá-las no mercado, gerando valor para clientes por meio do emprego de inovação, criatividade, relacionamentos e flexibilidade (HILLS; HULTMAN, 2013).

Entretanto, pouco se sabe sobre o efeito sinérgico das técnicas de marketing aplicadas em MPEs. Embora elas estejam presentes na literatura, os resultados da aplicação informal das estratégias de marketing na MPE ainda são pouco estudados, principalmente pela dificuldade de acesso às empresas (SOLÉ, 2013).

Dessa forma, o objetivo da pesquisa relatada neste artigo consiste em identificar no contexto das MPEs quais são as estratégias adotadas na gestão do marketing a partir da influência da aprendizagem dos gerentes-proprietários.

O aspecto motivador deste estudo é o interesse em ampliar a discussão sobre a temática no ambiente científico e estudos que foquem a realidade brasileira, devido à importância do perfil dessas empresas para a economia. De acordo com o Sebrae (2012), as MPEs representam 99\% das empresas instaladas no país e 50\% dos empregos nacionais.

Um aspecto identificado durante a fase exploratória da pesquisa evidenciou a carência de literatura científica nas bases de dados brasileiras (apenas seis) quando se busca a palavra-chave "marketing empreendedor" ou "gestão de marketing para pequenas empresas" no Scientific Periodicals Electronic Library (SPELL). Dessa forma, a contribuição do artigo consiste em apresentar quais as técnicas de marketing utilizadas pelos gerentes-proprietários na gestão das MPEs.

Para a condução desta pesquisa, foram adotadas duas fases. A primeira com caráter exploratório, para compreender a melhor linguagem a ser utilizada com os gerentes-proprietários. A segunda fase foi realizada por meio do envio de um questionário eletrônico. Para a estruturação do questionário foi considerado o de Moraes (2008) e as informações obtidas na fase exploratória, sendo enviado a empresas sediadas em Goiânia e região metropolitana.

COELHO, R. L. F.; MIRANDA, J. R.; CARMARGO FILHO, A.; FREITAG, M. S. B.; ALMEIDA, M. I. S. de. Gestão do marketing em micro e pequenas empresas. Revista de Empreendedorismo e Gestão de Pequenas Empresas, v.4, n.2, 2015. 
Além desta introdução, o presente estudo está organizado em quatro seções. Na segunda seção, são apresentados os principais conceitos teóricos que nortearam a pesquisa. Em seguida, são descritos os procedimentos metodológicos utilizados para a coleta e análise dos dados. Na quarta seção, são apresentados os resultados da pesquisa a partir das análises qualitativas e quantitativas, enquanto que a última seção discute as considerações finais do trabalho.

\section{Marketing}

Para a discussão de marketing empreendedor e sua aplicação no contexto de MPEs, este tópico tem como objetivo discorrer sobre o avanço do conhecimento em marketing.

No início dos estudos de marketing, o objetivo era direcionar o produto dos fornecedores até o consumidor. Atualmente, a discussão é mais ampla, de acordo com o conceito aprovado em 2013 pela American Marketing Association (AMA). Segundo a AMA (2013), marketing é uma "atividade, conjunto de instituições e processos para criar, comunicar, entregar e trocar ofertas que tenham valor para consumidores, clientes, parceiros e sociedade em geral".

Essa evolução do objetivo do marketing é descrita nas pesquisas de Tadajewski (2009) e Gamble (2011) ao mostrarem que o marketing evoluiu de uma condição de orientação para vendas para uma definição de relacionamento com o cliente e criação de valor. Dessa forma, o papel do marketing consiste em administrar a demanda de bens e serviços. E estimular o consumo de um produto que atenda as necessidades de um determinado grupo de pessoas. É um processo de trocas, no qual duas ou mais pessoas oferecem valor para o outro com o objetivo de satisfazer necessidades (SHULTZ, 2007). Por meio desse aperfeiçoamento, o marketing busca despertar desejos, em que já existe a necessidade para, assim, criar uma demanda. 


\section{Marketing empreendedor}

Harrison e Shaw (2004) caracterizam a pequena empresa por sua habilidade de resposta para o meio ambiente e pela capacidade intuitiva por parte do empreendedor em se antecipar às mudanças nas demandas dos clientes. Em uma abordagem de campo, os autores identificaram que reconhecimento de oportunidade, esforço empresarial, cultura e rede de relacionamento são temas predominantes na gestão de pequenas empresas.

Para Morrish (2011), a cultura das MPEs é largamente influenciada pelos atributos e valores do gerente-proprietário e impulsionada por sua atitude positiva em relação ao risco e inovação. Isso permite maior flexibilidade à medida que se estuda e explora oportunidades atrativas.

Segundo Harrigan, Ramsey e Ibbotson (2012), a pequena empresa possui algumas vantagens em relação às grandes organizações: incluem uma lealdade entre os funcionários, a proximidade com os clientes, a flexibilidade às necessidades do mercado e foco nas oportunidades. Isso contribui para a formação de um relacionamento mais próximo com o consumidor (CARSON, 1990; HARRIGAN; RAMSEY; IBBOTSON, 2012).

O problema geral na gestão do marketing de pequenas empresas consiste no fato de os gerentes-proprietários terem o conhecimento do produto ou serviço que está sendo oferecido aos clientes, mas não dominarem ações da área de marketing e, portanto, terem dificuldades em implementar ações de marketing (GILMORE et al., 2012). Logo, o marketing atua em um ambiente incerto, em que as condições do mercado são descontínuas e as necessidades do mercado não são claras (MARITZ; FREDERICK; VALOS, 2010).

Para Morris, Schindehutte, Laforge (2002) a gestão do marketing nas MPEs tem uma abordagem proativa e de exploração de oportunidades para aquisição e retenção de clientes rentáveis, por meio de tratamentos inovadores para a gestão de riscos, alavancagem de recursos e criação de valor. Martin (2009) aponta essa gestão como um processo não limitado ao gestor, mas adaptável aos ambientes corporativos.

COELHO, R. L. F.; MIRANDA, J. R.; CARMARGO FILHO, A.; FREITAG, M. S. B.; ALMEIDA, M. I. S. de. Gestão do marketing em micro e pequenas empresas. Revista de Empreendedorismo e Gestão de Pequenas Empresas, v.4, n.2, 2015. 
Já Carson (1990) e Solé (2013) dizem que os gestores-proprietários precisam adaptar as técnicas para praticá-las em suas empresas, e que esse "marketing praticado" é o chamado marketing empreendedor que integra características do empreendedorismo e marketing em MPEs.

A gestão do marketing no contexto das pequenas empresas foi primeiramente estudada nos Estados Unidos, por meio da união dos estudos entre marketing e empreendedorismo. Um levantamento feito por Hills, Hultman e Miles (2008) apresentou o início do tema no ambiente acadêmico. De acordo com os autores, o primeiro estudo sobre marketing em MPEs foi realizado em 1982 por Gerald Hills.

Em 1986, foi realizado o primeiro simpósio em marketing e empreendedorismo, e publicado o primeiro artigo com foco em empreendedorismo no Journal of Marketing. A partir de 1987, outros pesquisadores avançaram na discussão sobre o tema: Morris e Paul (1987), Carson (1990), McAuley (1995), Stokes (2000), dentre outros.

Carson (1990) e Stokes (2000) realizaram estudos que levaram o marketing nas pequenas empresas para duas trajetórias: foco do comportamento, liderada por Carson (1990) e foco no empreendedor como gestor, liderada por Stokes (2000). Na visão de Carson (1990), o marketing empreendedor é o fruto do modelo de gestão adotado pelos gerentes-proprietários. Assim, os resultados obtidos pela empresa são proporcionais às ferramentas de marketing que eles agregam e aplicam em seu cotidiano. Já para Stokes (2000), o marketing empreendedor está ligado ao perfil empreendedor do gestor e suas características é que vão promover o sucesso da empresa. Para o autor, o conhecimento, comportamento, formação acadêmica e experiência profissional do gestor influenciam suas ações de marketing no empreendimento.

Seguindo a linha voltada para a gestão em si, Carson (1990) dividiu as estratégias de marketing em quatro estágios para que as pequenas empresas sobrevivam no mercado: marketing reativo, na qual o gestor-proprietário usa sua rede de relacionamentos para angariar seus primeiros clientes; marketing de ajustes, quando o gestor passa a adotar estratégias de marketing espontâneas para aumentar as vendas; marketing empreendedor, caracterizado pela intuição e alto 
risco; e marketing proativo, que é aquele metódico, controlado e conduzido por um especialista contratado pela empresa.

Carson (1990) afirma que as pequenas empresas escolhem os métodos do marketing tradicional que melhor se adaptam à realidade da organização. Dessa forma, assim como a empresa tem de se adaptar ao mercado, o marketing deve se adaptar às capacidades e recursos da empresa. Essa limitação de recursos e capacidade faz com que o gerente-proprietário realize ações intuitivas e informais que se encaixem nos recursos da organização.

Nesse sentido, os empresários vão preferir um marketing mais interativo em vez da comercialização impessoal, pois mantêm um relacionamento próximo de seu mercado-alvo (STOKES, 2000). Para o autor, nas pequenas empresas, o diálogo entre cliente e empresário pode se tornar o único ponto de venda da empresa. Essa relação próxima entre dono do negócio e consumidor é uma vantagem competitiva para as pequenas organizações.

Em suma, nas pequenas empresas, o marketing é realizado pelos gerentesproprietários, usando táticas para atrair novos negócios, sem uma literatura didática disponível como o marketing tradicional (CARSON; GUILMORE, 2000). Além disso, para Stokes (2000), as pequenas empresas estão orientadas para a inovação e conduzidas pelas ideias e intuição, e não para o cliente e pela avaliação das necessidades do mercado.

\section{A aprendizagem gerencial: um esforço de mudança para o marketing no contexto da MPE}

Sabe-se que os gerentes-proprietários estão em grande envolvimento com o cotidiano do negócio, vivenciando um processo de aprendizagem por meio da reflexão sobre as ações desenvolvidas no dia a dia (FREITAG, 2012).

A aprendizagem gerencial é estudada internacionalmente por pesquisadores como Mintzberg e Gosling (2003), Tranfield, Denyer e Smart (2003) e Monks et al. (2007). Somando aos estudos desses pesquisadores, Ruas e Cominis (2007) destacam, em suas pesquisas, proposições sobre aprendizagem gerencial (Quadro 1).

COELHO, R. L. F.; MIRANDA, J. R.; CARMARGO FILHO, A.; FREITAG, M. S. B.; ALMEIDA, M. I. S. de. Gestão do marketing em micro e pequenas empresas. Revista de Empreendedorismo e Gestão de Pequenas Empresas, v.4, n.2, 2015. 
Quadro 1 - Proposições de melhorias para formação gerencial

\begin{tabular}{|l|l|}
\hline \multicolumn{1}{|c|}{ Pesquisadores } & \multicolumn{1}{c|}{ Ideias } \\
\hline $\begin{array}{l}\text { Mazen, Jones e } \\
\text { Sergenian (2000) }\end{array}$ & Transformar uma classe numa learning organization. \\
\hline Isabella (2005) & $\begin{array}{l}\text { O aprendizado deve ocorrer por meio de ações concretas em } \\
\text { disciplina voltada para o trabalho em equipe. }\end{array}$ \\
\hline Conger e Xin (2000) & $\begin{array}{l}\text { Métodos pedagógicos devem incluir aprendizagem na ação e } \\
\text { experiências diversificadas em situações específicas. }\end{array}$ \\
\hline $\begin{array}{l}\text { Raelin e Coghlan } \\
\text { (2006) }\end{array}$ & $\begin{array}{l}\text { Ressaltam a importância da relação com o trabalho e com o } \\
\text { ambiente organizacional nos processos de aprendizagem } \\
\text { gerencial. }\end{array}$ \\
\hline Mintzberg (2006) & Abordagem reflexiva para a formação gerencial. \\
\hline
\end{tabular}

Fonte: Adaptado de Ruas e Comini (2007)

No contexto nacional, a aprendizagem gerencial vem sendo estudada por pesquisadores como Antonello (2004, 2011a, 2011b), Bitencourt (2005) e Ruas e Comini (2007). Este último define esse tipo de aprendizagem como um processo de responsabilidade intrínseco ao indivíduo e abarca o conteúdo que emerge nas várias circunstâncias da vida. Alguns estudiosos consideram que a aprendizagem gerencial formal obtida em instituições de ensino é baseada em modelos mecanicistas do mundo industrializado e não atendem aos desafios atuais impostos pelas organizações (CLOSS; ANTONELLO, 2010). Nessa direção, Antonello (2011a) posiciona-se como adepta à abordagem reflexiva da aprendizagem, considerando a reflexão como fator importante na formação gerencial.

Além de contribuir para a amplitude da aprendizagem, esse fator influencia no que é aprendido e no processo de como aprender. Mesmo assim, o apoio à reflexão durante os processos de formação como elemento mediador da aprendizagem não é algo que ocorre nos programas destinados a esse tipo de formação gerencial. Ao invés disso, sob o ponto de vista de Ruas e Comini (2007), esses programas são fundamentados por currículos e disciplinas padronizadas empregando metodologias pedagógicas tradicionais que não estimulam a reflexão.

Leite, Godoy e Antonello (2006) consideram que a função gerencial pode ser suportada por várias formas de aprendizagem. As pesquisadoras, tendo como base Pozo (2002) apresentam duas categorias de aprendizagem: explícita e implícita. A primeira resulta de uma ação propositada, organizada e consciente, com um objetivo claro de aprendizado.

COELHO, R. L. F.; MIRANDA, J. R.; CARMARGO FILHO, A.; FREITAG, M. S. B.; ALMEIDA, M. I. S. de. Gestão do marketing em micro e pequenas empresas. Revista de Empreendedorismo e Gestão de Pequenas Empresas, v.4, n.2, 2015. 
Essa forma de aprendizagem relaciona-se ao modelo tradicional de aprendizagem gerencial que, conforme De Moraes, Da Silva e Cunha (2004), valoriza apenas a educação e o desenvolvimento gerencial formal, ou seja, que ocorrem em sala de aula. Por outro lado, a aprendizagem implícita ocorre fora do ambiente formal e de maneira não intencional. Esse modelo ganha crédito por ocorrer no próprio contexto do trabalho, possibilitando resultados melhores e mais rápidos.

Nesse sentido, Leite, Godoy e Antonello (2006), em uma pesquisa relacionada ao aprendizado da função gerencial por indivíduos, concluíram que:

- As habilidades gerenciais são aprendidas mediante experiências vivenciadas, de natureza marcante ou apenas corriqueiras;

- Ao serem desafiados, os gerentes desenvolvem novos comportamentos e atitudes, o que redunda em aprendizagem pela experiência;

- A participação em eventos explícitos de formação e a trajetória profissional são fluentes na aprendizagem gerencial;

- Entre as formas de aprendizagem pela experiência foram descobertas pelas pesquisadoras: a observação, as experiências contadas por outros e a aprendizagem por tentativa e erro.

Com base nas referências apresentadas, tem-se como pressupostos que a aprendizagem gerencial em marketing dos gerentes-proprietários de MPEs tem uma conotação implícita e ocorre pelas experiências do cotidiano e desafios com os quais se deparam no dia a dia, na medida em que vão identificando as demandas da área.

\section{Procedimentos metodológicos}

Para a operacionalização da pesquisa, a primeira etapa foi exploratória a fim de identificar estudos que pudessem contribuir na elaboração do questionário e que estivessem direcionados para a gestão de marketing em MPEs no Brasil, para que os fatores nacionais estivessem contemplados.

COELHO, R. L. F.; MIRANDA, J. R.; CARMARGO FILHO, A.; FREITAG, M. S. B.; ALMEIDA, M. I. S. de. Gestão do marketing em micro e pequenas empresas. Revista de Empreendedorismo e Gestão de Pequenas Empresas, v.4, n.2, 2015. 
A partir de uma pesquisa em bases nacionais de periódicos, foram identificados poucos trabalhos sobre o tema. Zoschke e Lima (2008) abordam a rede de relações empreendedoras e Limongi et al. (2012) discutem o tema em relação a ensino.

Com a dificuldade de identificação de materiais que fomentasse a elaboração do questionário, os autores pesquisaram em bases de teses e dissertações de universidades brasileiras. Foi localizada uma pesquisa de Moraes (2008), em que o autor utiliza um questionário que aborda: pesquisa e segmentação de mercado; produto; preço; promoção e comunicação; planejamento de marketing; estrutura de marketing e riscos.

A partir do questionário identificado, os autores analisaram as questões individualmente com a ajuda de um especialista em marketing, buscando melhorias para o questionário e alinhamento com o objetivo da pesquisa. Ao final, decidiram aplicar um pré-teste com cinco gerentes-proprietários. O resultado do pré-teste mostrou a necessidade de adequar a semântica das questões e o tempo de resposta.

A versão final do questionário abordou, inicialmente, de forma qualitativa, como os respondentes conceituavam marketing e a forma de definição do perfil do público que pretendem atingir. A segunda parte continha os seguintes grupos: clientes, concorrentes, redes de relacionamento, planejamento e pesquisa de marketing, preço, produto e estrutura de marketing.

A população-alvo era de gerentes-proprietários de empresas com sede em Goiânia ou na região metropolitana, enquadradas como MPE. A coleta de dados ocorreu por meio do envio de um questionário eletrônico no Google Drive e os autores contaram com o apoio da Associação de Jovens Empreendedores de Goiás (AJE), que auxiliaram enviando o questionário para sua mala direta com 82 empreendedores. O total de respondentes foi de 52. Porém, 12 foram descartados por não terem informado características como faturamento, tempo no mercado e quantidade de empregados.

Para análise dos dados, foram adotadas as abordagens quantitativas e qualitativas. A análise qualitativa utilizou a análise de discurso. A análise quantitativa ocorreu por meio da análise de conglomerados (clusters) que, segundo Fávero et al.

COELHO, R. L. F.; MIRANDA, J. R.; CARMARGO FILHO, A.; FREITAG, M. S. B.; ALMEIDA, M. I. S. de. Gestão do marketing em micro e pequenas empresas. Revista de Empreendedorismo e Gestão de Pequenas Empresas, v.4, n.2, 2015. 
(2009), tem como objetivo, agrupar elementos com características homogêneas. O método utilizado foi o de vínculo entre grupos com variáveis padronizadas e a distância quadrática euclidiana. O software SPSS Statistics, versão 21 , foi utilizado para as análises quantitativas.

\section{Análise dos resultados: característica dos respondentes}

Dentre o perfil dos respondentes, foram levantadas três características: gênero, faixa etária e formação acadêmica. Destes, $62 \%$ são do gênero masculino e $38 \%$ do gênero feminino. 58\% têm entre 30 e 40 anos e $22 \%$ entre 25 e 29 anos. 42\% responderam que possuem curso superior e 40\% possuem pós-graduação. Na Tabela 1 é apresentada a descrição completa dos perfis.

Tabela 1 - Característica dos respondentes

\begin{tabular}{|l|l|l|c|l|l|}
\hline \multicolumn{2}{|c|}{ Gênero } & \multicolumn{2}{c|}{ Faixa Etária } & \multicolumn{2}{c|}{ Formação Acadêmica } \\
\hline Masculino & $62 \%$ & Entre 20 e 24 anos & $2 \%$ & Ensino Fundamental & $4 \%$ \\
\hline Feminino & $38 \%$ & Entre 25 e 29 anos & $22 \%$ & Ensino Médio & $14 \%$ \\
\hline & & Entre 30 e 40 anos & $58 \%$ & Superior & $42 \%$ \\
\hline & & Mais de 41 anos & $18 \%$ & Pós-graduação & $40 \%$ \\
\hline
\end{tabular}

Fonte: Os autores (2015).

Em relação ao perfil das empresas, identificou-se uma maioria do segmento de serviço (66\%). O tempo no mercado das empresas ficou balanceado, 36\% entre 5 e 10 anos, 34\% a partir de 11 anos e 30\% entre 1 e 4 anos. Sobre o faturamento das empresas, 36\% faturam entre $R \$ 360.000,01 \mathrm{e}$ $R \$ 3.6$ milhões, e $28 \%$ entre $R \$ 60.000,01$ e $R \$ 360.000$.

A Tabela 2 apresenta as informações detalhadas do perfil das empresas.

Tabela 2 - Característica das empresas

\begin{tabular}{|l|l|l|l|l|l|}
\hline \multicolumn{2}{|c|}{ Segmento } & \multicolumn{2}{c|}{ Tempo } & \multicolumn{2}{c|}{ Faturamento em 2013 } \\
\hline Comércio & $14 \%$ & Entre 1 e 4 anos & $30 \%$ & Até $\mathrm{R} \$ 60.000,00$ & $23,8 \%$ \\
\hline Indústria & $20 \%$ & Entre 5 e 10 anos & $36 \%$ & $\begin{array}{l}\text { Entre } \mathrm{R} \$ 60.000,01 \text { e } \mathrm{R} \$ \\
360.000,00\end{array}$ & $33,3 \%$ \\
\hline Serviço & $66 \%$ & A partir de 12 anos & $34 \%$ & $\begin{array}{l}\text { Entre } \mathrm{R} \$ 360.000,01 \text { e } \\
\mathrm{R} \$ 3,6 \text { milhões. }\end{array}$ & $42,9 \%$ \\
\hline
\end{tabular}

Fonte: Os autores (2015).

COELHO, R. L. F.; MIRANDA, J. R.; CARMARGO FILHO, A.; FREITAG, M. S. B.; ALMEIDA, M. I. S. de. Gestão do marketing em micro e pequenas empresas. Revista de Empreendedorismo e Gestão de Pequenas Empresas, v.4, n.2, 2015. 


\section{Marketing para os gerentes-proprietários}

Para melhor compreensão de como os gerentes-proprietários entendem marketing, o questionário contemplou uma questão aberta na qual o respondente poderia colocar qual seu conceito de marketing. Retomando o conceito da AMA (2013) e quando relacionadas às definições dadas pelos gerentes-proprietários, tem-se que: para $40 \%$ dos entrevistados marketing é divulgação da marca, produto ou serviço, e em geral não há entendimento de criação e troca de valor ou relação e comunicação com o cliente.

Os gerentes-proprietários definiram o marketing como: ferramentas utilizadas para divulgar e vender produtos ou serviços, método para alavancar as vendas, ações que buscam visibilidade, dentre outros. As palavras que mais aparecem foram: divulgação, vendas, ações, estratégia e produto.

Para compreender a análise qualitativa, a Tabela 3 mostra por meio de categorização, as palavras mais citadas nas respostas e quantas vezes elas aparecem ao considerar a morfologia da palavra.

Tabela 3 - Frequência das palavras mais citadas nos conceitos de marketing a partir dos respondentes

\begin{tabular}{|l|c|}
\hline \multicolumn{1}{|c|}{ PALAVRAS-CHAVENAS RESPOSTAS } & FREQUËNCIA EM QUE SÃO CITADAS \\
\hline DIVULGAÇÃO & 16 \\
\hline AÇÕES & 10 \\
\hline ESTRATÉGIA & 8 \\
\hline PRODUTO & 16 \\
\hline CLIENTE & 14 \\
\hline
\end{tabular}

Fonte: Os autores (2015).

De maneira livre, uma formulação do conceito de marketing para os gerentes-proprietários seria: "ações e estratégias de divulgação do produto para o cliente". É possível afirmar que o marketing para um gerente-proprietário tem um sentido diferente do conceito da AMA (2013). Este fato é esperado devido à informalidade do estágio intitulado de marketing empreendedor.

A Tabela 4 relaciona as palavras-chave da definição da AMA (2013) e quantas vezes essas palavras são citadas pelos respondentes:

COELHO, R. L. F.; MIRANDA, J. R.; CARMARGO FILHO, A.; FREITAG, M. S. B.; ALMEIDA, M. I. S. de. Gestão do marketing em micro e pequenas empresas. Revista de Empreendedorismo e Gestão de Pequenas Empresas, v.4, n.2, 2015. 
Tabela 4 - Frequência das palavras-chave de marketing nos conceitos dados pelos respondentes

\begin{tabular}{|c|c|}
\hline $\begin{array}{c}\text { PALAVRAS-CHAVE DO CONCEITO DE MARKETING } \\
\text { DA AMA (2013) }\end{array}$ & $\begin{array}{l}\text { FREQUÊNCIA EM QUE SÃO } \\
\text { CITADAS NAS RESPOSTAS }\end{array}$ \\
\hline PROCESSOS & 6 \\
\hline TROCA & 2 \\
\hline VALOR & 2 \\
\hline CONSUMIDOR & 6 \\
\hline CLIENTE & 14 \\
\hline
\end{tabular}

Fonte: Os autores (2015).

Apenas a palavra "cliente" é citada 14 vezes e nenhum dos respondentes cita atividade, criação, comunicação ou oferta. O marketing informado são ações para promover suas empresas no mercado, não havendo entendimento de que as ações que eles praticam são técnicas adaptadas por eles mesmos para a realidade de suas empresas.

Outras respostas obtidas foram que o marketing seria "ações estratégicas que visam criar valor para o cliente por meio dos produtos e/ou serviços que a empresa oferece a fim de se atingir o objetivo principal da empresa, o lucro". Para este grupo, o objetivo do marketing é criar valor para o cliente por meio de produtos ou serviços.

\section{Aprendendo com o planejamento e a pesquisa de marketing}

A partir do questionário aplicado, foram analisadas duas questões que evidenciam a temática de aprendizagem gerencial. Na Tabela 5 é possível verificar, de maneira descritiva, o resultado destas questões. 
Tabela 5 - Questões e respostas com a temática de aprendizagem

\begin{tabular}{|l|c|c|}
\hline \multicolumn{1}{|c|}{ OPÇÃo DE RESPOSTAS } & $\begin{array}{c}\text { QUANTIDADE DE } \\
\text { RESPOSTAS }\end{array}$ & PORCENTAGEM \\
\hline Experiência anterior de vendas & 27 & $31 \%$ \\
\hline Reuniões de planejamento & 20 & $23 \%$ \\
\hline Pesquisa de mercado & 17 & $20 \%$ \\
\hline $\begin{array}{l}\text { Minha empresa não define o público que } \\
\text { vai atingir }\end{array}$ & 10 & $11 \%$ \\
\hline Recomendação dos fornecedores & 10 & $11 \%$ \\
\hline $\begin{array}{l}\text { Brainstorming com os sócios } \\
\text { colaboradores da empresa }\end{array}$ & 1 & $1 \%$ \\
\hline $\begin{array}{l}\text { Percepção do mercado / sentimento de } \\
\text { como está o mercado }\end{array}$ & 1 & $1 \%$ \\
\hline Segmento de comunicação & 1 & $1 \%$ \\
\hline \multicolumn{1}{|c|}{ Como sua empresa procura entender a necessidade de seus clientes? } \\
\hline OPÇÃo DE RESPOSTAS & $\begin{array}{c}\text { QUANTIDADE DE } \\
\text { RESPOSTAS }\end{array}$ & PORCENTAGEM \\
\hline $\begin{array}{l}\text { Observando o comportamento dos } \\
\text { clientes }\end{array}$ & 39 & 37 \\
\hline Observação do mercado & 37 & 35 \\
\hline Pesquisa de satisfação & 18 & 17 \\
\hline Caixa de sugestões e comentários & 8 & 8 \\
\hline $\begin{array}{l}\text { Diálogo com o cliente presenciando o } \\
\text { problema vivido in loco }\end{array}$ & 1 & 1 \\
\hline Reuniões com equipe de vendas & 1 & 1 \\
\hline Monitoramento da concorrência & 1 & 1 \\
\hline Font: Os autores (2015) & & $1 \%$ \\
\hline
\end{tabular}

Fonte: Os autores (2015).

Para a análise dos resultados optou-se pela estrutura teórico-metodológica denominada de paradigma de análise apresentada na Figura 1 (CASSIANI; CALIRI; PELÁ, 1996). Foram escolhidas as questões com maior quantidade de respostas e com maior relação com a aprendizagem para a análise.

COELHO, R. L. F.; MIRANDA, J. R.; CARMARGO FILHO, A.; FREITAG, M. S. B.; ALMEIDA, M. I. S. de. Gestão do marketing em micro e pequenas empresas. Revista de Empreendedorismo e Gestão de Pequenas Empresas, v.4, n.2, 2015. 


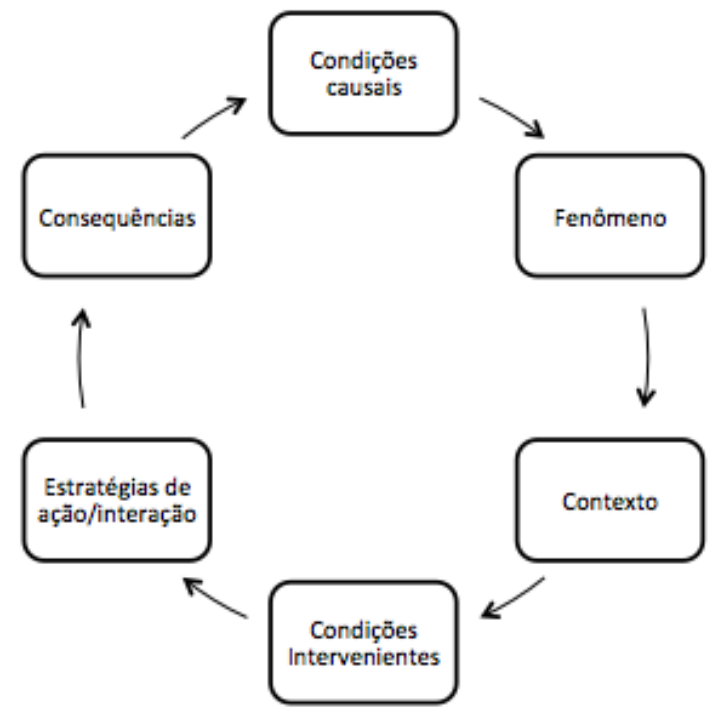

Figura 1 - Modelo de análise evolutiva/reflexiva de dados Fonte: Cassiani, Caliri e Pelá (1996).

Para elucidar o modelo, as codificações apresentadas na Figura 1 referemse a:

- Condições causais: são definidos eventos, incidentes e acontecimentos que causam a ocorrência do fenômeno;

- Fenômeno: ideia central, evento, acontecimento e incidente que motivam ações ou interações relacionadas;

- Contexto: propriedades que pertencem ao fenômeno. Condições dentro das quais são tomadas as estratégias de ação/interação;

- Condições intervenientes: condições estruturais que se apoiam nas estratégias de ação/interação e que pertencem ao fenômeno, podendo facilitar ou bloquear as estratégias tomadas;

- Estratégias de ação/interação: adotadas para responder ao fenômeno;

- Consequências: resultado ou expectativas da ação/interação.

$\mathrm{Na}$ análise das respostas às questões 1 e 2, conforme Quadro 5, buscou-se identificar os sentidos da aprendizagem nas falas dos gerentes-proprietários, por meio da análise do discurso, na qual os discursos não são apenas um conjunto de falas e, portanto, é preciso interpretar os seus sentidos, avançando na interpretação. 
O enunciado não diz tudo e ao mesmo tempo permite interpretações diferentes. Assim, é preciso a interpretação dos sentidos para sair do enunciado e chegar ao enunciável (CAREGNATO; MUTTI, 2006).

Nessa direção, a partir dos elementos do modelo de análise (Figura 1), foi elaborado o Quadro 2 para apresentar uma análise evolutiva/reflexiva das respostas às questões 1 e 2 "por meio das experiências anteriores de vendas" e "observando o comportamento dos clientes", respectivamente.

Quadro 2 - Codificação das questões sobre aprendizagem (evolução dos eventos indicativos das categorias de análise)

\begin{tabular}{|c|c|c|c|c|c|c|c|}
\hline Questões & $\begin{array}{l}\text { Condiç } \\
\text { ões } \\
\text { causai } \\
\mathbf{s}\end{array}$ & $\begin{array}{c}\text { Fenôm } \\
\text { eno }\end{array}$ & $\begin{array}{c}\text { Contex } \\
\text { to }\end{array}$ & $\begin{array}{c}\text { Condiçõe } \\
\text { s } \\
\text { interveni } \\
\text { entes }\end{array}$ & $\begin{array}{l}\text { Estratégi } \\
\text { as de } \\
\text { ação/inter } \\
\text { ação }\end{array}$ & $\begin{array}{c}\text { Consequê } \\
\text { ncias }\end{array}$ & $\begin{array}{l}\text { Categori } \\
\text { a de } \\
\text { análise }\end{array}$ \\
\hline $\begin{array}{l}\text { Q1 Como } \\
\text { sua } \\
\text { empresa } \\
\text { define o } \\
\text { perfil do } \\
\text { público } \\
\text { que } \\
\text { deseja } \\
\text { atingir? } \\
\text { Resposta } \\
\text { : por meio } \\
\text { das } \\
\text { experiênci } \\
\text { as } \\
\text { anteriores } \\
\text { de vendas }\end{array}$ & $\begin{array}{l}\text { Cliente } \\
\text { s } \\
\text { potenci } \\
\text { ais }\end{array}$ & Venda & $\begin{array}{l}\text { Mercad } \\
\text { o } \\
\text { consum } \\
\text { idor }\end{array}$ & $\begin{array}{l}\text { Situação } \\
\text { de } \\
\text { demanda } \\
\text { por } \\
\text { produtos } \\
\text { ou } \\
\text { serviços }\end{array}$ & $\begin{array}{l}\text { Adotar } \\
\text { competên } \\
\text { cia de } \\
\text { vender }\end{array}$ & $\begin{array}{l}\text { Saber } \\
\text { definir o } \\
\text { perfil do } \\
\text { público } \\
\text { que deseja } \\
\text { atingir }\end{array}$ & $\begin{array}{l}\text { Geração } \\
\text { de } \\
\text { conhecim } \\
\text { ento } \\
\text { sobre o } \\
\text { perfil do } \\
\text { público. } \\
\text { Quem } \\
\text { são os } \\
\text { clientes? } \\
\text { Aprendiz } \\
\text { agem } \\
\text { sobre o } \\
\text { público }\end{array}$ \\
\hline $\begin{array}{l}\text { Q2 Como } \\
\text { sua } \\
\text { empresa } \\
\text { procura } \\
\text { entender } \\
\text { a } \\
\text { necessida } \\
\text { de de } \\
\text { seus } \\
\text { clientes? } \\
\text { Resposta } \\
\text { s: } \\
\text { Observan } \\
\text { do o } \\
\text { comporta }\end{array}$ & $\begin{array}{l}\text { Saber } \\
\text { quem } \\
\text { são os } \\
\text { clientes }\end{array}$ & $\begin{array}{l}\text { Informa } \\
\text { ção }\end{array}$ & $\begin{array}{l}\text { Mercad } \\
\text { o } \\
\text { consum } \\
\text { idor }\end{array}$ & $\begin{array}{l}\text { Frequênci } \\
\text { a de } \\
\text { contato } \\
\text { com os } \\
\text { clientes }\end{array}$ & $\begin{array}{l}\text { Criar } \\
\text { eventos } \\
\text { de } \\
\text { atração, } \\
\text { manutenç } \\
\text { ão e } \\
\text { retenção } \\
\text { do cliente }\end{array}$ & $\begin{array}{l}\text { Entender } \\
\text { as } \\
\text { necessida } \\
\text { des do } \\
\text { cliente }\end{array}$ & $\begin{array}{l}\text { Geração } \\
\text { de } \\
\text { conhecim } \\
\text { ento } \\
\text { sobre as } \\
\text { demanda } \\
\text { s do } \\
\text { público } \\
\text { Aprendiz } \\
\text { agem } \\
\text { sobre as } \\
\text { expectati } \\
\text { vas dos } \\
\text { clientes } \\
\text { O que } \\
\text { eles }\end{array}$ \\
\hline
\end{tabular}

COELHO, R. L. F.; MIRANDA, J. R.; CARMARGO FILHO, A.; FREITAG, M. S. B.; ALMEIDA, M. I. S. de. Gestão do marketing em micro e pequenas empresas. Revista de Empreendedorismo e Gestão de Pequenas Empresas, v.4, n.2, 2015. 


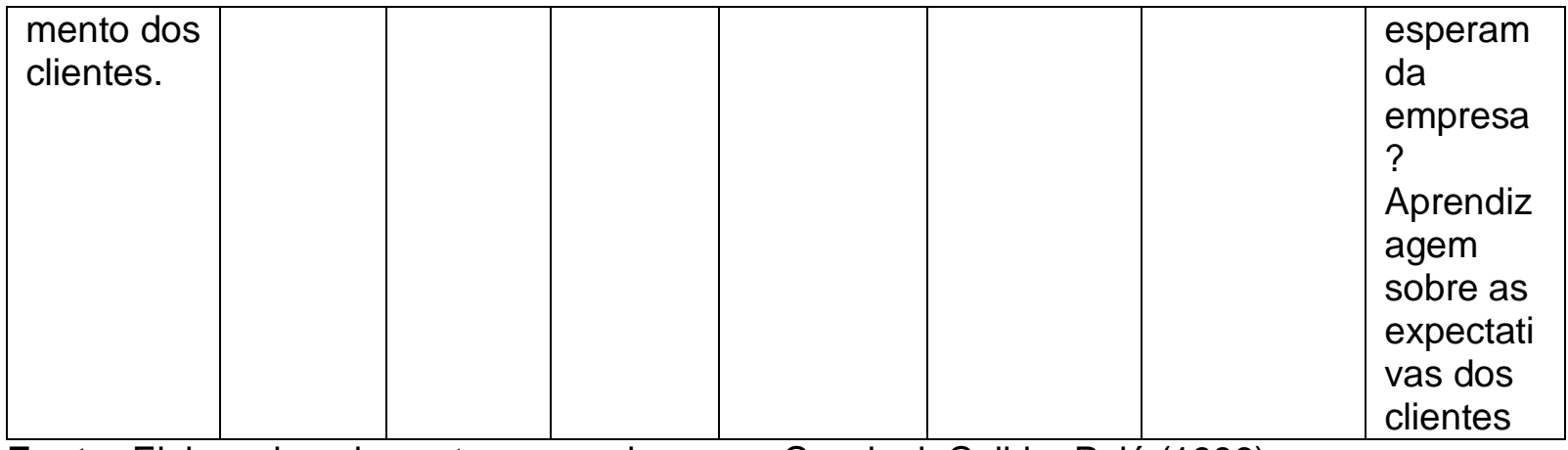

Fonte: Elaborado pelos autores com base em Cassiani, Caliri e Pelá (1996)

Conforme Leite, Godoy e Antonello (2006), uma das formas de aprendizagem acerca do exercício da função gerencial ocorre mediante experiências vivenciadas. Observando a evolução dos eventos presentes no Quadro 8, no percurso entre as condições causais até a aprendizagem, pode-se inferir a existência de várias experiências sequenciadas. Dessa forma, a análise das respostas não deve ser feita considerando os discursos apenas como um conjunto de falas, mas sim avançar na interpretação.

Os sentidos são percebidos como fluindo a partir das interações entre as pessoas, não sendo, portanto, caracterizados como algo intrínseco (HAGUETTE, 1992). É preciso considerar que a resposta resulta das interações entre o respondente e o conjunto de elementos presentes no fenômeno estudado e, ainda, aquilo que tem relação com 0 perfil do respondente: 0 tempo como empresário/gestor, a idade, a formação, a natureza do negócio escolhido, entre outros.

Fazendo uma análise adicional à interpretação dos sentidos do discurso, apresenta-se outra forma de análise à resposta "por meio de experiências anteriores de vendas". Inicialmente, pode-se inferir que os saberes inerentes às experiências de vendas anteriores resultaram de reflexões sobre essas experiências, o que tornou possível a apropriação na definição do público que eles desejam atingir.

Compreende-se também que esse tipo de dinâmica de aprendizagem demanda processos contínuos de ação e de reflexão (LEITE; GODOY; ANTONELLO, 2006). Explorando mais ainda a interpretação das falas em discussão, é possível compreender que a experiência de aprendizagem destes respondentes para definição do público-alvo pode ser analisada por meio do Ciclo 
de Aprendizagem Vivencial (CAV) de Kolb (1997). Este ciclo compreende as fases de vivência concreta, observação reflexiva, conceituação abstrata e experimentação ativa, as quais serão descritas a seguir.

- Experiência concreta: a prática de vendas anteriores. Essa prática proporciona contato direto com situações que demandaram posicionamentos diante de situações de dilemas. Por exemplo, como é comum na área de vendas, para fechar o negócio é preciso a tomada de decisão entre alterar o preço ou prazo de pagamento. As decisões tomadas amparadas em conhecimentos anteriores, os saberes adquiridos nesse momento, no ciclo de aprendizagem servindo como insumos para futuras aprendizagens;

- Observação reflexiva: as decisões tomadas para fechar as vendas demandando informações sobre a realidade interna, por exemplo, o do fluxo de caixa e o capital de giro. Esse tipo de situação é resultante de agrupamentos de informações refletidas acerca do que é percebido, deixando fluir as dificuldades, possibilidades e opiniões sobre as alternativas que afloram durante o processo de observação;

- Conceituação abstrata: nas falas dos empresários respondentes afirmando que definem o público que desejam atingir com base nas experiências anteriores na área de vendas, indicando que eles construíram conceitos abstratos sobre as experiências mencionadas e transportaram esses conceitos no momento em que definiram o público de seus negócios. Esse tipo de conceituação é favorecido pela qualidade da observação reflexiva e pode contribuir para a formação de um tronco conceitual para atender diferentes demandas relacionadas à situação refletida;

- Experiência ativa: a apropriação dos saberes adquiridos com base nas experiências anteriores com vendas possibilitando aos empresários saber definir o público-alvo nos seus negócios. Constituindo-se, portanto, em uma aplicação prática dos conhecimentos refletidos e apropriados daquilo que Ihes foram solicitados.

Os respondentes da pesquisa que têm uma definição sobre o público a atingir, produto de uma forma de agir sistematizada ou não, passaram por experiências relacionadas às fases do ciclo de aprendizagem vivencial descrita ALMEIDA, M. I. S. de. Gestão do marketing em micro e pequenas empresas. Revista de Empreendedorismo e Gestão de Pequenas Empresas, v.4, n.2, 2015. 
anteriormente. Essas experiências reforçam a intuição dos respondentes ajudandoos a interpretar a dinâmica do mercado.

O modelo de aprendizagem vivencial utilizado durante a análise é entendido por alguns autores (ANTONELLO, 2004, 2011a, 2011b; REYNOLDS, 2009; VILLARDI;VERGARA, 2011) como uma alternativa positiva para a aprendizagem gerencial. Reynolds (2009) sugere que além de favorecer a aprendizagem gerencial, esse tipo de alternativa, tendo uma característica reflexiva, pode ainda contribuir para tratar dos valores sociais e políticos inseridos no contexto organizacional.

\section{Análise de conglomerado}

Após a inadequação da análise fatorial, os autores decidiram utilizar a análise de conglomerado por ter como saída, agrupamentos homogêneos em relação ao perfil dos gerentes-proprietários, o que facilitaria a identificação de perfis dos indicadores levantados junto aos respondentes.

Retomando a análise da Tabela 2, os autores identificaram que a amostra obtida possuía diferenças entre três características: segmento, tempo no mercado e faturamento. Estas características representam a diversidade do perfil das empresas MPEs. Logo, optou-se por agrupar os respondentes a partir das características acima e verificar uma eventual existência de homogeneidade.

Por meio do método WARD, para identificar a quantidade de agrupamentos possíveis, os autores avaliaram a possibilidade de utilizar até três agrupamentos. Porém, buscando maior congruência entre os agrupamentos, foi realizada uma nova tentativa, dessa vez com apenas dois. O resultado com apenas dois agrupamentos (Figura 2) evidenciou o perfil dos respondentes: o Agrupamento 1 com empresas entre 1 e 11 anos no mercado e o Agrupamento 2 a partir de 12 anos, destacando assim uma diferença entre o perfil dos respondentes.

Com a definição por dois agrupamentos, foi gerado o dendograma para a confirmação da viabilidade de dois agrupamentos e posterior decisão sobre a 
condução das análises. A Figura 2 confirma a viabilidade com dois agrupamentos devido à similaridade entre os grupos.

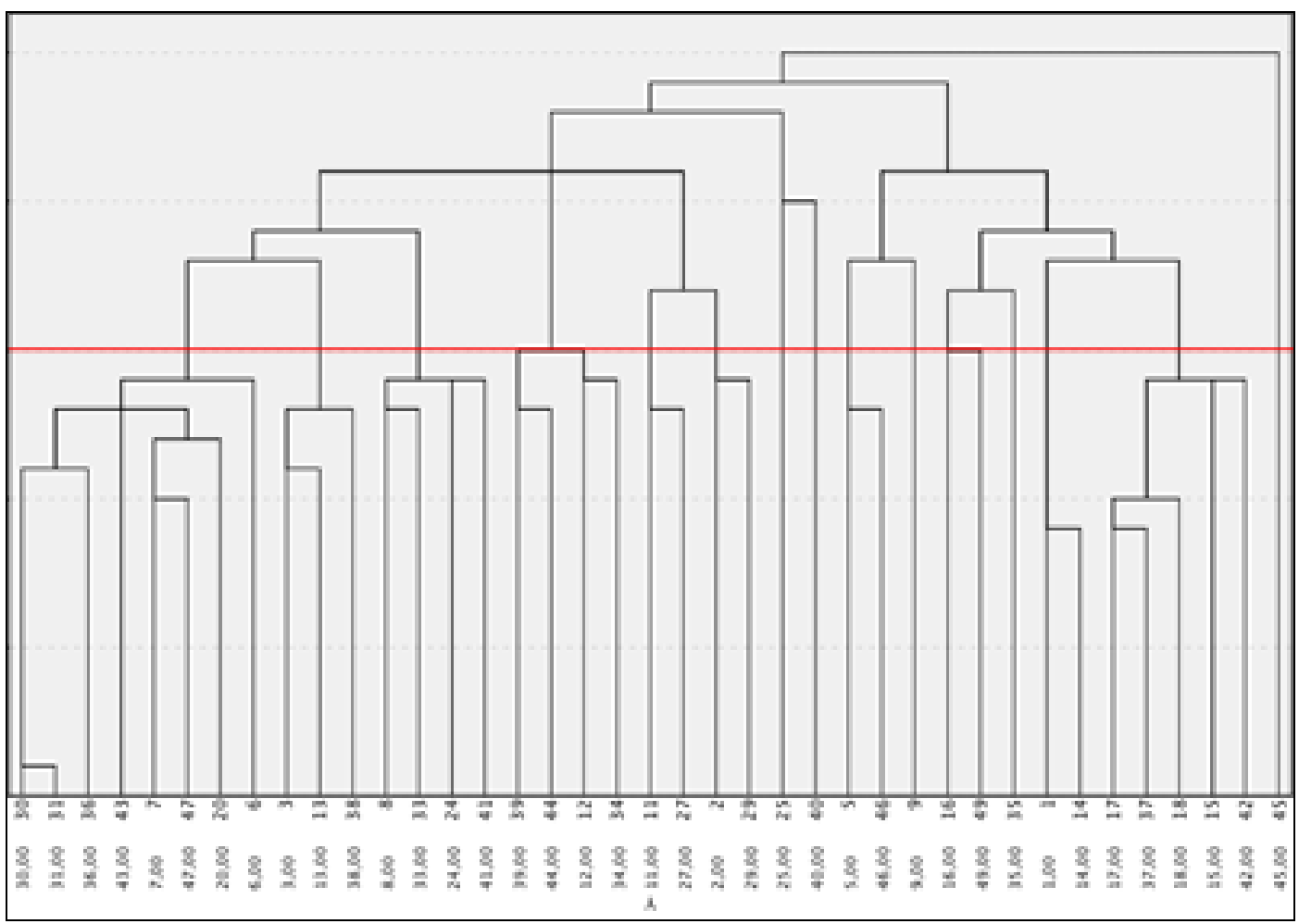

Figura 2 - Dendograma.

Fonte: Os autores (2015).

Com a decisão por dois agrupamentos para análise, o passo seguinte foi identificar a quantidade de respondentes por agrupamento.

$\mathrm{Na}$ Tabela 6, foram identificadas 20 empresas para o Agrupamento 1 e 20 para o Agrupamento 2, o que apresenta estar balanceado a partir do método WARD

Tabela 6 - Número de casos em cada agrupamento

\begin{tabular}{|ll|l|}
\hline Agrupamento & 1 & 20,000 \\
& 2 & 20,000 \\
\hline
\end{tabular}

Fonte: Os autores (2015).

Agrupamento 1 tem como preponderância, empresas que atuam no segmento de serviços. O tempo no mercado é a partir de 11 anos e possuem 
acima de 11 funcionários. O faturamento está entre $R \$ 360.000,01$ e $R \$$ 3.600.000,00. O Agrupamento 2 também tem como preponderância a atuação no segmento de serviços. Possuem entre 1 e 10 anos de atuação no mercado, e o faturamento é entre $R \$ 60.0000$ e $R \$ 360.000$.

Com a definição dos agrupamentos, foi elaborado o Quadro 3, que consolida a maior frequência a partir das questões respondidas para facilitar a análise dos indicadores.

Quadro 3 - Tabela resumo das técnicas de marketing a partir de dois agrupamentos

\begin{tabular}{|c|c|c|}
\hline Notação & Agrupamento 1 & Agrupamento 2 \\
\hline \multicolumn{3}{|l|}{ Comunicação } \\
\hline \multicolumn{3}{|l|}{ Cliente } \\
\hline $\begin{array}{l}\text { Ligo para clientes } \\
\text { quando eles visitam } \\
\text { minha empresa e não } \\
\text { compram }\end{array}$ & Sempre realiza & Frequentemente \\
\hline $\begin{array}{lr}\text { Distribuo } & \text { cartões } \\
\text { quando encontra } \\
\text { alguém que demonstra } \\
\text { interesse em um } \\
\text { produto/serviço na } \\
\text { área que atuo }\end{array}$ & Frequentemente & Sempre realiza \\
\hline $\begin{array}{l}\text { Faço panfletagem em } \\
\text { lugares propícios a } \\
\text { potenciais clientes }\end{array}$ & Raramente & Frequentemente \\
\hline $\begin{array}{l}\text { Decoro minha } \\
\text { empresa para chamar } \\
\text { a atenção }\end{array}$ & Nunca realiza & Sempre realiza \\
\hline $\begin{array}{l}\text { Faço propagandas em } \\
\text { mídias como TV, rádio, } \\
\text { jornal, e outros }\end{array}$ & Raramente & Às vezes \\
\hline $\begin{array}{l}\text { Patrocino eventos } \\
\text { locais que, em troca, } \\
\text { divulgo minha marca }\end{array}$ & Raramente & Frequentemente \\
\hline $\begin{array}{l}\text { Distribuo brindes que } \\
\text { possuem o nome ou } \\
\text { logotipo da empresa }\end{array}$ & Às vezes & Às vezes \\
\hline $\begin{array}{l}\text { Faço promoções para } \\
\text { atrair clientes }\end{array}$ & Às vezes & Sempre realiza \\
\hline $\begin{array}{l}\text { Envio SMS, cartas ou } \\
\text { e-mail para o cliente } \\
\text { com informações de } \\
\text { promoções ou novos } \\
\text { produtos }\end{array}$ & Nunca realiza & \\
\hline $\begin{array}{ll}\text { Movimento } & \text { uma } \\
\text { página em uma rede }\end{array}$ & Às vezes & Sempre realiza \\
\hline
\end{tabular}

COELHO, R. L. F.; MIRANDA, J. R.; CARMARGO FILHO, A.; FREITAG, M. S. B.; ALMEIDA, M. I. S. de. Gestão do marketing em micro e pequenas empresas. Revista de Empreendedorismo e Gestão de Pequenas Empresas, v.4, n.2, 2015. 


\begin{tabular}{|c|c|c|}
\hline $\begin{array}{lr}\text { social } & \text { com } \\
\text { informações } & \text { da } \\
\text { empresa } & \\
\end{array}$ & & \\
\hline $\begin{array}{l}\text { Peço a seus clientes } \\
\text { atuais que indiquem } \\
\text { minha } \\
\text { empresa/produto para } \\
\text { outras pessoas }\end{array}$ & Frequentemente & Sempre realiza \\
\hline $\begin{array}{l}\text { Faço confraternização } \\
\text { com os clientes atuais } \\
\text { ou potenciais }\end{array}$ & Nunca realiza & Raramente \\
\hline $\begin{array}{l}\text { Ligo para o cliente } \\
\text { após a venda para } \\
\text { saber se ele ficou } \\
\text { satisfeito }\end{array}$ & Raramente & Sempre realiza \\
\hline $\begin{array}{l}\text { Ofereço desconto para } \\
\text { clientes que indicaram } \\
\text { a empresa ou sempre } \\
\text { consomem meus } \\
\text { produtos/serviços }\end{array}$ & Frequentemente & Frequentemente \\
\hline \multicolumn{3}{|l|}{ Concorrente } \\
\hline $\begin{array}{l}\text { Em que você } \\
\text { considera que sua } \\
\text { empresa se diferencia } \\
\text { dos concorrentes? }\end{array}$ & Atendimento de qualidade & Atendimento de qualidade \\
\hline \multicolumn{3}{|l|}{ Rede de relacionamento } \\
\hline $\begin{array}{l}\text { De qual meio social ou } \\
\text { pessoal você utiliza } \\
\text { para atrair novos } \\
\text { clientes para sua } \\
\text { empresa? }\end{array}$ & Eventos/Encontros & Eventos/Encontros \\
\hline \multicolumn{3}{|c|}{ Planejamento e pesquisa de marketing } \\
\hline $\begin{array}{l}\text { Como sua empresa } \\
\text { define o perfil do } \\
\text { público que deseja } \\
\text { atingir? }\end{array}$ & $\begin{array}{l}\text { Experiência de vendas } \\
\text { anteriores }\end{array}$ & Reuniões de planejamento \\
\hline $\begin{array}{l}\text { Como sua empresa } \\
\text { procura entender a } \\
\text { necessidade de seus } \\
\text { clientes? }\end{array}$ & $\begin{array}{c}\text { Observando o } \\
\text { comportamento dos clientes }\end{array}$ & $\begin{array}{c}\text { Observando o comportamento } \\
\text { dos clientes }\end{array}$ \\
\hline $\begin{array}{llr}\text { Como } & \text { você } & \text { fica } \\
\text { sabendo } & \text { o que } & \text { os } \\
\text { clientes pensam } & \text { a } \\
\text { respeito } & \text { de } & \text { sua } \\
\text { empresa? } & & \\
\end{array}$ & Elogios diretos & Por meio das redes sociais \\
\hline $\begin{array}{l}\text { Partindo do } \\
\text { pressuposto que você } \\
\text { analisa as ações de } \\
\text { seus concorrentes, } \\
\text { qual o objetivo desta } \\
\text { análise? }\end{array}$ & Proteger meu negócio & Proteger meu negócio \\
\hline
\end{tabular}

COELHO, R. L. F.; MIRANDA, J. R.; CARMARGO FILHO, A.; FREITAG, M. S. B.; ALMEIDA, M. I. S. de. Gestão do marketing em micro e pequenas empresas. Revista de Empreendedorismo e Gestão de Pequenas Empresas, v.4, n.2, 2015. 


\begin{tabular}{|c|c|c|}
\hline $\begin{array}{lr}\text { Qual a frequência que } \\
\text { você realiza a } \\
\text { pesquisa } \\
\text { satisfação? }\end{array}$ & Raramente & Frequentemente \\
\hline $\begin{array}{l}\text { Qual a frequência que } \\
\text { você realiza a } \\
\text { pesquisa } \\
\text { definição do público- } \\
\text { alvo? }\end{array}$ & Nunca realiza & Frequentemente \\
\hline $\begin{array}{l}\text { Qual a frequência que } \\
\text { você faz o teste de } \\
\text { aceitação dos novos } \\
\text { produtos? }\end{array}$ & Raramente & Frequentemente \\
\hline \multicolumn{3}{|l|}{ Preço e Produto } \\
\hline $\begin{array}{l}\text { Quais dessas ações } \\
\text { sua empresa realiza } \\
\text { ao introduzir novos } \\
\text { produtos no mercado? }\end{array}$ & $\begin{array}{c}\text { Não realiza nenhuma ação } \\
\text { específica }\end{array}$ & $\begin{array}{l}\text { Oferece produtos para } \\
\text { demonstração e testes }\end{array}$ \\
\hline $\begin{array}{l}\text { Como você determina } \\
\text { o preço dos produtos } \\
\text { ou serviços da sua } \\
\text { empresa? }\end{array}$ & Custo mais lucro & $\begin{array}{l}\text { Preço baseado no valor } \\
\text { praticado no mercado }\end{array}$ \\
\hline \multicolumn{3}{|l|}{ Estrutura de marketing } \\
\hline $\begin{array}{l}\text { Sua empresa tem um } \\
\text { planejamento escrito } \\
\text { de marketing? }\end{array}$ & Não & Sim \\
\hline $\begin{array}{l}\text { Até dezembro/2012 } \\
\text { sua empresa possuía } \\
\text { alguma } \\
\text { pessoa/departamento } \\
\text { responsável pelo } \\
\text { marketing? }\end{array}$ & Não & Não \\
\hline $\begin{array}{l}\text { Você tem orçamento } \\
\text { de marketing fixado } \\
\text { para o ano de } 2014 \text { ? }\end{array}$ & Não & Não \\
\hline
\end{tabular}

Fonte: Os autores (2015).

A partir da análise do Quadro 3, é possível observar que as empresas do Agrupamento 2, de maneira geral, aplicam, de forma mais ampla, as técnicas de marketing apresentadas. Este grupo de empresas está mais em contato com o cliente, com maiores frequências de ações como distribuição de cartões, telefonemas pós-venda ou panfletagem. Para Carson (1990), empresas em início de mercado buscam se beneficiar de forma mais intensa das comunicações boca a boca de sua rede de relacionamentos, quando se encontram potenciais clientes.

Observa-se um distanciamento das empresas do Agrupamento 1 em relação à comunicação com o cliente. Para Stokes (2000), os pequenos empresários têm COELHO, R. L. F.; MIRANDA, J. R.; CARMARGO FILHO, A.; FREITAG, M. S. B.; ALMEIDA, M. I. S. de. Gestão do marketing em micro e pequenas empresas. Revista de Empreendedorismo e Gestão de Pequenas Empresas, v.4, n.2, 2015. 
preferência pelo marketing interativo ao invés da comercialização impessoal, o que faz que estejam mais próximos do mercado alvo. As empresas do Agrupamento 1, por terem uma estrutura mais complexa que as do Agrupamento 2, podem estar perdendo essa proximidade com os clientes.

Em relação aos posicionamentos diante dos concorrentes, ambos os Agrupamentos identificaram a qualidade do atendimento como um diferencial. De forma geral, o contato dos clientes com os donos dos negócios nas MPEs é mais fácil do que nas grandes corporações (STOKES, 2000). Assim, esses empresários levam vantagens em relação a grandes empresas no sentido de serem capazes de participar ativamente no contato com o cliente, garantindo a qualidade do atendimento.

Em relação aos produtos, as empresas do Agrupamento 2 são mais propensas a fazer demonstrações com seus possíveis clientes. Esse comportamento tem relação com a aprendizagem pela observação do comportamento de grandes empresas. A definição do preço de venda das empresas do Agrupamento 1 é feita a partir de quanto os empresários esperam lucrar pelos produtos. Esse comportamento é esperado para esse grupo, visto que são empresas já estabelecidas no mercado. Por serem novas no mercado e precisarem conquistar seus clientes, as MPEs descritas no Agrupamento 2 observam os preços dos concorrentes para formarem os seus.

Ambos os agrupamentos realizam ações semelhantes no que diz respeito ao planejamento de marketing, definindo público-alvo e as necessidades dos clientes por meio de experiências passadas e observação do mercado. Isso vai de encontro com a constatação de Stokes (2000), ao afirmar que o processo de marketing empreendedor está intimamente ligado à intuição dos empreendedores sobre as expectativas do mercado. Uma diferença constatada é que as empresas mais recentes fazem o uso das redes sociais virtuais para conhecer a opinião de seus clientes, mostrando que são mais dinâmicas e atualizadas com as transformações do mercado.

Técnicas do marketing tradicional, como pesquisas de satisfação, definição do público-alvo e planejamento formal de marketing, são utilizadas mais amplamente pelas empresas do Agrupamento 2. Isso mostra que os empresários das empresas 
mais recentes possuem mais técnica e conhecimento formal do que aqueles proprietários das empresas do Agrupamento 1. Para Moraes (2008), as ações do marketing tradicional, se bem utilizadas, podem auxiliar na prevenção de situações de risco e no processo de tomada de decisões.

Em relação à estrutura de marketing, os dois agrupamentos não contam com orçamento dedicado para a área, nem um responsável pelo marketing, ou seja, todas as empresas se encontram no estágio do marketing empreendedor, sem uma estrutura formal para esta área.

Dessa forma, e de acordo com o Quadro 3, é possível verificar as estratégias de marketing utilizadas pelos gerentes-proprietários nas MPEs e fomentar a discussão para se analisar características inerentes às empresas de maneira separada para verificar o comportamento das estratégias e seus resultados.

\section{Considerações finais}

O principal objetivo deste estudo foi identificar, no contexto das MPEs, quais as estratégias adotadas na gestão do marketing a partir da influência da aprendizagem dos gerentes-proprietários. Os objetivos específicos consistiram em: analisar o que os gestores-proprietários conceituam como marketing; analisar as ações voltadas para o marketing segundo a comunicação, preço, produto, planejamento e estrutura de marketing; e, por fim, verificar a influência da aprendizagem dos gerentes proprietários.

Analisando o objetivo principal, verifica-se que as MPEs pesquisadas possuem características diferentes: o tempo de atuação varia de 1 a 37 anos; o número de funcionários de 1 a 57; e o faturamento de $R \$ 100.000,00$ a $\mathrm{R} \$ 1.800 .000,00$. A maior parte das empresas, cerca de $66 \%$, são prestadores de serviço, $20 \%$ são comércio e $14 \%$ são indústrias.

O primeiro objetivo específico teve como foco analisar o que gerentesproprietários entendem por marketing. Por meio de uma categorização de frequência com que algumas palavras são citadas nas respostas qualitativas, verificou-se que os gerentes-proprietários conceituam o marketing como 
ferramenta de divulgação. Usando as palavras mais utilizadas, formulou-se o seguinte conceito: "ações e estratégias de divulgação do produto para o cliente". O que difere do conceito da AMA (2013), de que o marketing é criação e troca de valor entre partes negociantes.

Os resultados do segundo objetivo específico geraram discussão. Quanto à comunicação com o cliente, é possível inferir que acontece por meio de uma relação próxima, com diálogos, encontros casuais e atendimento. Por meio disso, os gerentes-proprietários tanto apresentam suas empresas e produtos quanto recebem o feedback do cliente em relação às suas expectativas, satisfações e necessidades. A pesquisa de mercado é utilizada com pouca frequência e é por meio das conversas informais que o gerente-proprietário obtém a maior parte das informações do seu cliente.

Em relação à análise do concorrente, pode-se dizer que acontece na forma de percepção do mercado. $O$ empreendedor se mune de informações dos seus concorrentes para antecipar sua ação e se proteger de um marketing mais consolidado, típico das grandes empresas. A maior parte dos respondentes informou que $o$ atendimento de qualidade é o que os diferencia de seus concorrentes. Essa diferenciação se dá pela proximidade que a MPE tem com seus clientes.

Sobre as estratégias de produto e preço, foi verificado que as empresas não têm uma metodologia definida para testar novos produtos, nem de pesquisa de preço. O que está de acordo com a teoria de Stokes (2000), de que o empreendedor é inovador, mas as avaliações para o mercado são intuitivas, pois os gestoresproprietários agem de forma amadora nas relações produto/mercado, realizando ações de acordo com a percepção que possui do ambiente de mercado.

Em relação ao planejamento de marketing é possível inferir que a definição de público-alvo das empresas pesquisadas é baseada no feeling do empresário, ou seja, no "sentimento" que ele tem do ambiente mercadológico.

A partir dos dados levantados e analisados, pode-se inferir que as atividades de marketing nas MPEs ainda são feitas de forma intuitiva. Não há pesquisa ou estudo para implantar uma atividade. Elas são realizadas de acordo com o feeling do empresário. Além disso, nas MPEs, é utilizada a rede de contatos dos gerentes-proprietários e o relacionamento próximo com o cliente como a ALMEIDA, M. I. S. de. Gestão do marketing em micro e pequenas empresas. Revista de Empreendedorismo e Gestão de Pequenas Empresas, v.4, n.2, 2015. 
principal fonte de informações da empresa. Esse tipo de estratégia adotada propicia oportunidades de aprendizagem e se constitui como elemento importante no fortalecimento da gestão. A interpretação dos sentidos de alguns discursos revela a presença dessas oportunidades.

Assim, na análise do discurso das respostas das questões "como sua empresa define o perfil do público que deseja atingir?" (tendo como resposta "por meio das experiências anteriores de vendas") e "como sua empresa procura entender a necessidade de seus clientes?" (tendo como resposta "observando o comportamento dos clientes"), mostra evidências que é mediante as práticas cotidianas que os respondentes vão descobrindo as estratégias que se adequam ao cotidiano.

Com isto, simultaneamente, os gerentes-proprietários vão tomando decisões e desenvolvendo novos conceitos sobre o negócio em um processo permanente de aprendizagem. As experiências anteriores, que se somam com as vivências do cotidiano, redundam numa aprendizagem gerencial de marketing mais fortalecida para o amanhã.

Por fim, é preciso salientar que no decorrer deste trabalho, algumas dificuldades surgiram como limitantes da pesquisa: há pouco estudo realizado sobre marketing empreendedor no Brasil e a resistência por parte de empresários para responder ao questionário. Embora seja revestido de importância, o tema ainda é pouco estudado no Brasil.

Recomenda-se, então, u ma pesquisa mais aprofundada em cada área do marketing empreendedor, como networking, feedback, definição de público-alvo e segmentação, dentre outras. Outra sugestão para pesquisa futura seria mensurar a importância das estratégias de marketing por meio da análise de regressão para verificar a influência sobre o faturamento, por exemplo, assim poderia ser analisado o resultado de cada estratégia no resultado das MPEs.

\section{Referências:}

AMA - American Marketing Association, 2013. Disponível em:< http://www.marketingpower.com/AboutAMA/Pages/DefinitionofMarketing.aspx>. Acesso em: 11 fev. 2014.

COELHO, R. L. F.; MIRANDA, J. R.; CARMARGO FILHO, A.; FREITAG, M. S. B.; ALMEIDA, M. I. S. de. Gestão do marketing em micro e pequenas empresas. Revista de Empreendedorismo e Gestão de Pequenas Empresas, v.4, n.2, 2015. 
ANTONELLO, C. S.. As formas de aprendizagem utilizadas por gestores no desenvolvimento de competências. In: XXVIII ENCONTRO NACIONAL DA ASSOCIAÇÃO NACIONAL DOS PROGRAMAS DE PÓS-GRADUAÇÃO EM ADMINISTRAÇÃO - ENANPAD, 28, 2004. Rio de Janeiro, Anais... Rio de Janeiro: ANPAD, 2004.

ANTONELLO, C. S. Contextos do saber. A aprendizagem informal. Aprendizagem organizacional no Brasil. Porto Alegre: Bookman, 2011.

ANTONELLO, C. S. Saberes no singular? A falsa fronteira entre aprendizagem formal e informal. Aprendizagem organizacional no Brasil. Porto Alegre: Bookman, 2011.

BITENCOURT, C.. A gestão de competências como alternativa de formação e desenvolvimento nas organizações: uma reflexão crítica baseada na percepção de um grupo de gestores. Os novos horizontes da gestão: aprendizagem organizacional e competências. Porto Alegre: Bookman, 2005.

CAREGNATO, R. C. A.; MUTTI, R. Pesquisa qualitativa: análise de discurso versus análise de conteúdo. Texto Contexto Enferm, v. 15, n. 4, p. 679-84, 2006.

CARSON, D. Some exploratory models for assessing small firms' marketing performance (a qualitative approach). European Journal of Marketing, v. 24, n. 11, p. 8-51, 1990.

CARSON, D; GILMORE, A. SME marketing management competencies. International Business Review, v. 9, n. 3, p. 363-382, 2000.

CASSIANI, S. B.; CALIRI, M. H. L.; PELÁ, N. T. R.. A teoria fundamentada nos dados como abordagem da pesquisa interpretativa. Rev Latino-am Enfermagem, v. 4, n. 3, p. 75-88, 1996.

CLOSS, L. Q.; ANTONELLO, C. S. Aprendizagem Transformadora: Integrando a Reflexão Crítica na Formação Gerencial. GESTÃO. Org-Revista Eletrônica de Gestão Organizacional, v. 6, n. 1, 2010.

CONGER, J. A.; XIN, K.. Executive education in the 21st century. Journal of Management Education, v. 24, n. 1, p. 73-101, 2000. 
ELMUTI, D.; KHOURY, G.; OMRAN, O.. DOES ENTREPRENEURSHIP EDUCATION HAVE A ROLE IN DEVELOPING ENTREPRENEURIAL SKILLS AND VENTURES'EFFECTIVENESS?. Journal of Entrepreneurship Education, v. 15, 2012.

FÁVERO, L. P.; BELFIORE, P.; SILVA, F. L. da; CHAN, B. L.. Análise de Dados: Modelagem Multivariada para Tomada de Decisões. Rio de Janeiro: Elsevier, 2009.

FREITAG, M. S. B.. A Consultoria Interna como Espaço Para a Conversão do Conhecimento. REGE Revista de Gestão, v. 19, n. 1, 2012.

GAMBLE, J. The Marketing concept in the 21st century: A review of how Marketing has been defined since the 1960s. The Marketing Review, v. 11, n. 3, p. 227-248, 2011.

GILMORE, A.; KRAUS, S.; O’ DWYER, M.; MILES, M. Editorial: Strategic marketing management in small and medium-sized enterprises. International Entrepreneurship and Management Journal, v. 8, n. 2, p. 141-143, 2012.

HAGUETTE, T. M. F.. Metodologias qualitativas na sociologia. 1992.

HARRIGAN, P.; RAMSEY, E.; IBBOTSON, P.. Entrepreneurial marketing in SMEs: the key capabilities of e-CRM. Journal of Research in Marketing and Entrepreneurship, v. 14, n. 1, p. 40-64, 2012.

HARRISON, P. J.; SHAW, R. N. Intra-organisational marketing culture and market orientation: a case study of the implementation of the marketing concept in a public library. Library management, v. 25, n. 8/9, p. 391-398, 2004.

HILLS, G. E.; HULTMAN, C. M. Entrepreneurial Marketing: Conceptual and empirical research opportunities. Entrepreneurship Research Journal, v. 3, n. 4, p. 437-448, 2013.

HILLS, G. E.; HULTMAN, C. M.; MILES, M. P. The evolution and development of entrepreneurial marketing. Journal of Small Business Management, v. 46, n. 1, p. 99-112, 2008.

ISABELLA, L. A. Using existing teams to teach about teams: How an MBA course in managing teams helps students and the program. Journal of Management Education, v. 29, n. 3, p. 427-452, 2005.

COELHO, R. L. F.; MIRANDA, J. R.; CARMARGO FILHO, A.; FREITAG, M. S. B.; ALMEIDA, M. I. S. de. Gestão do marketing em micro e pequenas empresas. Revista de Empreendedorismo e Gestão de Pequenas Empresas, v.4, n.2, 2015. 
JONES, R.; ROWLEY, J.. Entrepreneurial marketing in small businesses: a conceptual exploration. International Small Business Journal, v. 29, n. 1, p. 25-36, 2011.

KOLB, D. A. A gestão e o processo de aprendizagem. STARKEY, K. Como as organizações aprendem: relatos do sucesso das grandes empresas. São Paulo: Futura, 1997.

LEITE, I. C. B. V.; GODOY, A. S.; ANTONELLO, C. S.. O aprendizado da função gerencial: os gerentes como atores e autores do seu processo de desenvolvimento. Aletheia, n. 23, p. 27-41, 2006.

LIMONGI, R.; TETE, M. F.; DE ALMEIDA, M. I. S.; BORGES, C . Ensino do marketing empreendedor: descrição e análise comparativa de experiências realizadas em duas regiões brasileiras/Education marketing entrepreneur: description and comparative analysis of experiments conducted in two brazilian regions. Revista da Micro e Pequena, v. 6, n. 3, p. 58-73, 2012..

MARITZ, A.; FREDERICK, H.; VALOS, M.. A discursive approach to entrepreneurial marketing: integrating academic and practice theory. Small Enterprise Research, v. 17, n. 1, p. 74-86, 2010.

MARTIN, D. M. The entrepreneurial marketing mix. Qualitative Market Research: An International Journal, v. 12, n. 4, p. 391-403, 2009.

MAZEN, A. M.; JONES, M. C.; SERGENIAN, G. K. Transforming the class into a learning organization. Management Learning, v. 31, n. 2, p. 147-161, 2000.

MCAULEY, A. An assessment of research into the internationalisation process. GE Hills et al., p. 331-42, 1995.

MINTZBERG, H. MBA? Não, obrigado: uma visão crítica sobre a gestão eo desenvolvimento de gerentes. Porto Alegre: Bookman, 2006.

MINZTBERG, H.; GOSLING, J. Educando administradores além das fronteiras. RAE-Revista de Administração de Empresas, v. 43, n. 2, p. 29-43, 2003.

MONKS, K., CONWAY, E., BUCKLEY, F., O'SHEA, D., KIRRANE, M., BAGRAIM, J., BANNISTER, B., NEUMANN, R. The impact of individual and organisational factors on the psychological empowerment of managers and knowledge workers: A

COELHO, R. L. F.; MIRANDA, J. R.; CARMARGO FILHO, A.; FREITAG, M. S. B.; ALMEIDA, M. I. S. de. Gestão do marketing em micro e pequenas empresas. Revista de Empreendedorismo e Gestão de Pequenas Empresas, v.4, n.2, 2015. 
transnational study. 9th International Human Resource Management Conference, Tallin: Estonia, 2007.

MORAES, C. P. Marketing Empreendedor nas Empresas Distribuidoras do Setor Industrial da 3M do Brasil LTDA: Estudo na Região Sul do Brasil. $137 \mathrm{f}$. Dissertação (Mestrado em Administração) - Centro de Ciências Sociais Aplicadas, Universidade Regional de Blumenau, Blumenau, 2008.

MORAES, L. V. S.; DA SILVA, M. A.; CUNHA, C. J. C. A. Aprendizagem gerencial: teoria e prática. RAE-eletrônica, v. 3, n. 1, p. 1-21, 2004.

MORRIS, M. H.; PAUL, G. W. The relationship between entrepreneurship and marketing in established firms. Journal of Business Venturing, v. 2, n. 3, p. 247259, 1987.

MORRIS, M. H.; SCHINDEHUTTE, M.; LAFORGE, R. W. Entrepreneurial marketing: a construct for integrating emerging entrepreneurship and marketing perspectives. Journal of marketing theory and practice, p. 1-19, 2002.

MORRISH, S. C. Entrepreneurial marketing: a strategy for the twenty-first century?. Journal of Research in Marketing and Entrepreneurship, v. 13, n. 2, p. 110-119, 2011.

POZO, J. I. Aprendizes e mestres: a nova cultura da aprendizagem. Artmed, 2002.

RAELIN, J. A.; COGHLAN, D. Developing managers as learners and researchers: Using action learning and action research. Journal of Management Education, v. 30, n. 5, p. 670-689, 2006.

REYNOLDS, M. Wild frontiers-reflections on experiential learning. Management Learning, v. 40, n. 4, p. 387-392, 2009.

RUAS, R.; COMINI, G. M. Aprendizagem e desenvolvimento de competências: articulando teoria e prática em programas de pós-graduação em formação gerencial. Cadernos EBAPE. BR, v. 5, n. SPE, p. 01-14, 2007.

SERVIÇO BRASILEIRO DE APOIO À MICRO E PEQUENA EMPRESA. Boletim Estudos \& Pesquisas: Importância das MPE na geração de empregos em anos de crise 2012.

Disponível em:

COELHO, R. L. F.; MIRANDA, J. R.; CARMARGO FILHO, A.; FREITAG, M. S. B.; ALMEIDA, M. I. S. de. Gestão do marketing em micro e pequenas empresas. Revista de Empreendedorismo e Gestão de Pequenas Empresas, v.4, n.2, 2015. 
<http://www.biblioteca.sebrae.com.br/bds/BDS.nst/23695F6CAE7EAC7683257AD30 0 40A7D7/\$File/NT000482B2.pdf.> Acesso em: 19 fev. 2014.

SHULTZ, C. J. Marketing as constructive engagement. Journal of Public Policy \& Marketing, v. 26, n. 2, p. 293-301, 2007.

SOLÉ, M. Entrepreneurial marketing: conceptual exploration and link to performance. Journal of Research in Marketing and Entrepreneurship, v. 15, n. 1, p. 23-38, 2013.

STOKES, D. Putting entrepreneurship into marketing: the processes of entrepreneurial marketing. Journal of Research in Marketing and Entrepreneurship, v. 2, n. 1, p. 1-16, 2000.

TADAJEWSKI, M. Eventalizing the marketing concept. Journal of Marketing Management, v. 25, n. 1-2, p. 191-217, 2009.

TRANFIELD, D; DENYER, D; SMART, P. Towards a methodology for developing evidence-informed management knowledge by means of systematic review. British journal of management, v. 14, n. 3, p. 207-222, 2003.

VILLARDI, B. Q.; VERGARA, S. C. Implicações da Aprendizagem Experiencial e da Reflexão Pública para o Ensino de Pesquisa Qualitativa ea Formação de Mestres em Administração. Revista de Administração Contemporânea-RAC, Curitiba, v. 15, n. 5, p. 794-814, 2011.

ZOSCHKE, A. C. K.; LIMA, E. O. Marketing empreendedor e redes de relação: um estudo sobre micro, pequenas e médias empresas. Gestão \& Planejamento-G\&P, v. 1 , n. $14,2008$. 